\title{
Effect of Summer Holidays on Anthropometric Measures and Body Composition of Older Adults, Inadequacy of Body Mass Index to Detect Changes During a Critical Period: A Pilot Study
}

\author{
Efecto de las Vacaciones de Verano en la Composición Corporal de Adultos Mayores, \\ Insuficiencia del Índice de Masa Corporal para Detectar Cambios Durante un Período \\ Crítico: Un Estudio Piloto
}

Pablo A. Lizana*; Rubén López ${ }^{* *}$ \& Cecilia Albala***

LIZANA, P. A.; LÓPEZ, R. \& ALBALA, C. Effect of summer holidays on anthropometric measures and body composition of older adults, inadequacy of body mass index to detect changes during a critical period: A pilot study. Int. J. Morphol., 34(2):557-560, 2016.

SUMMARY: Obesity is a major health problem worldwide. Obesity prevalence in Chilean older adults (OA) is increasing, associated with several negative health outcomes. Therefore, determining critical periods of adiposity increase is relevant in OA. The aim of the study was to assess body composition changes in OA during summer holidays. This observational study involved two test visits, without a control group. Twelve OA ( 9 females) with an average age of $71.92 \pm 6.97$ years participated in an initial evaluation (E1) and final evaluation (E2) at the beginning and at the end of the summer in 2015. Weight, height, and body mass index (BMI) were assessed; fat-free mass (FFM), fat mass (FM), and muscular mass (MM) data were collected through foot-to-foot bioimpedance analysis. No significant variations were reported in weight and BMI between E1 and E2. This prevalence was maintained between E1 and E2. The FM significantly increased between E1 (27.63 \pm 10.91$)$ and E2 $(28.64 \pm 11.39)(\mathrm{p}=0.007)$, while the FFM significantly decreased between E1 (45.38 \pm 5.89$)$ and E2 (44.33 \pm 5.36$)(\mathrm{P}=0.006)$, also the MM between E1 (43.08 \pm 5.62$)$ and E2 (42.07 \pm 5.10$)$. Both, weight and BMI are insufficient measures for detecting changes during this critical summer holiday period. However, the body composition measures identified significant changes in the OA during the study.

KEY WORDS: Sarcopenia; Body fat; Obesity; Bioelectrical impedance.

\section{INTRODUCTION}

In Chile, approximately $73.6 \%$ of older adults (OA) are overweight (Body Mass Index (BMI) $\geq 25$ ) of these 30.9 $\%$ are obese (BMI $\geq$ to 30) (MINSAL, 2011). The nutritional evaluation for OA is widely based on BMI, and, in Chile, the existing OA nutritional evaluations are referenced by BMI (MINSAL, 2015). However, evidence indicates that OA present changes in their body composition that are not captured by BMI, such as decreases in fat free mass (FFM) through lost muscle mass (MM) and increases in fat mass (FM) (Gómez-Cabello et al., 2012). This phenomenon of increasing $\mathrm{BF}$ and decreasing $\mathrm{MM}$ has recently been defined as sarcopenic obesity (SO), which refers to high levels of $\mathrm{BF}$ and low levels of MM predisposing individuals to the development of cardiometabolic diseases and higher levels of functional dependence (Janssen et al., 2002; Parr et al., 2013; Ryan \& Nicklas, 1999). Additionally, decreased bone mass may also imply bone fragility, increasing fracture risk (Berry et al., 2014) and mobility limitations. This phenomenon reveals the necessity for identifying factors which affect body composition in OA. It has been reported that holidays may influence these changes due to increased caloric intake and decreased physical activity during this time (Payab et al., 2015; Stevenson et al., 2013). Because of this, summer holiday presents a critical period of body composition changes in OA that may allow us to prevent obesity and sarcopenia. Therefore, the aim of this study was to evaluate possible anthropometric and body composition changes in OA during a summer holiday.

\footnotetext{
* Laboratory of Morphological Sciences, Instituto de Biología, Pontificia Universidad Católica de Valparaíso, Valparaíso, Chile.

** Escuela de Kinesiología, Pontificia Universidad Católica de Valparaíso, Valparaíso, Chile.

**** Nutrition and Public Health, Aging, and Genetic Epidemiology Unit, Institute of Nutrition and Food Technology, Universidad de Chile, Santiago, Chile.
} 


\section{SUBJECT AND METHOD}

This observational study involved two test visits and was conducted on all OA at a meetinghouse in Curauma, province of Valparaíso, a region of Valparaíso, Chile $(\mathrm{n}=$ 28). The researcher explained to the OA the objectives of the study and its procedures; 12 OA ( 9 women) gave their informed consent to participate in the study. The subjects, with a mean age of 71.92 \pm 6.97 years old (range: 60-81), were initially evaluated in two visits: late-January, before summer vacation starts (E1) and mind-March, immediately following (E2) summer vacation in OA, the interval between assessments was 49 days (January 26th to March 16th 2015).

Weight was measured using an electronic scale (Seca 813), and height was evaluated using the mobile stadiometer seca 217 to calculate BMI in kilograms per square meter $\left(\mathrm{kg} / \mathrm{m}^{2}\right)$. Nutritional state categories based on BMI were determined using Chilean reference guides for $\mathrm{OA}$ : overweight BMI 28-31.9, obesity BMI $\geq 32$ (MINSAL, 2015). Body composition measures of FM, FFM, and MM were assessed using foot-to-foot bioelectrical impedance tetrapolar analysis (Tanita BC 420SMA, Tokyo, Japan). OA were asked to refrain from consuming alcohol, caffeine, diuretics and participating in vigorous exercise in the $24 \mathrm{~h}$ prior to measurement. In addition, the participants were asked to empty their bladders before the measurements. The measurements were taken without any metallic jewelry on and with only light clothing on the patients. All the measurements were collected at the OA meetinghouse. Anthropometric and body composition measurements were assessed by the first (PAL) author of the present study.
For statistical analyses, means, standard deviations and percentages of the anthropometric variables and body composition were calculated. Data sets were checked for normality using Shapiro-Wilk normality test. The paired Mann-Whitney U-test was used to assess if differences existed between before and after the summer break. Statistical analysis was performed using STATA software version12.0. $\mathrm{p}$-value of $<0.05$ was used to indicate statistical significance.

\section{RESULTS}

Baseline characteristics of all study subjects and change in all outcome variables between E1 and E2 are shown in Table I. The participants had a mean height of $1.56 \pm 0.52 \mathrm{~m}$, which was consistent in both evaluations. The

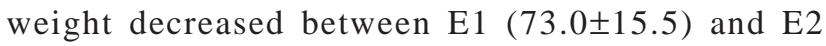
$(72.9 \pm 15.7)(\mathrm{P}=0.784)$, while BMI increased by 0.04

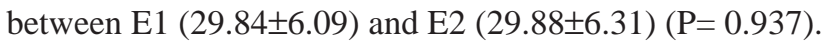
Regarding to BMI categories, $58.3 \%$ were eutrophic, $8.3 \%$ were overweight and $33 \%$ were obese. The percentages of participants who fell into these categories did not change from E1 to E2.

A significant increase was found between E1 (27.63 \pm 10.91$)$ and E2 (28.64 \pm 11.39$)$ in FM $(\mathrm{P}=0.007)$, and a significant decrease was found between E1 (45.38 \pm 5.89$)$ and E2 (44.33 \pm 5.36$)(\mathrm{P}=0.006)$ in FFM, and between $\mathrm{E} 1$ (43.08 \pm 5.62$)$ and E2 (42.07 \pm 5.10$)$ in MM $(P=0.006)$. Figures 1 to 3 showed changes in FM, FFM, and MM in each subject. There were eleven subjects $(91.67 \%)$ whose FM

Table I. Anthropometric measures and body composition changes of older adults from Valparaíso, Chile ( $\mathrm{n}=12)$. Summer holidays (January-March) 2015.

\begin{tabular}{lcccc}
\hline Variables & Before & After & Change & P-value $^{\mathbf{b}}$ \\
\hline Age (years) & $71.92 \pm 6.97$ & --- & --- & --- \\
Sex (female) & $\mathrm{n}=9(75 \%)$ & --- & --- & --- \\
Weight $(\mathrm{kg})$ & $73.0 \pm 15.5$ & $72.9 \pm 15.7$ & $-0.1 \pm 0.2$ & 0.784 \\
Height $(\mathrm{m})$ & $1.56 \pm 0.52$ & $1.56 \pm 0.52$ & --- & --- \\
Body Mass Index & $29.84 \pm 6.09$ & $29.88 \pm 6.31$ & $0.04 \pm 0.52$ & 0.937 \\
$<23$ & $\mathrm{n}=0(0 \%)$ & $\mathrm{n}=0(0 \%)$ & --- & --- \\
$23.1-27.9$ & $\mathrm{n}=7(58.33 \%)$ & $\mathrm{n}=7(58.33 \%)$ & --- & --- \\
$28-31.9$ & $\mathrm{n}=1(8.33 \%)$ & $\mathrm{n}=1(8.33 \%)$ & --- & --- \\
$\geq 32$ & $\mathrm{n}=4(33.33 \%)$ & $\mathrm{n}=4(33.33 \%)$ & --- & --- \\
Fat Mass (kg) & $27.63 \pm 10.91$ & $28.64 \pm 11.39$ & $1.01 \pm 1.06$ & $0.007^{*}$ \\
Fat Free Mass $(\mathrm{kg})^{\mathrm{a}}$ & $45.38 \pm 5.89$ & $44.33 \pm 5.36$ & $-1.05 \pm 0.97$ & $0.006^{*}$ \\
Muscle Mass $(\mathrm{kg})^{\mathrm{a}}$ & $43.08 \pm 5.62$ & $42.07 \pm 5.10$ & $-1.01 \pm 0.93$ & $0.006^{*}$
\end{tabular}

Values presented as Means \pm SD, and frequency and percentage. $\mathrm{a}=$ Assessed by bioimpedance (TANITA BC420MA). $b=$ Changes in measured variables from pre-to post summer holiday season were tested using paired Mann-Whitney $\mathrm{U}$ test. *= Indicate significant change from pre-to post-holiday season $(\mathrm{p}<0.05)$. 


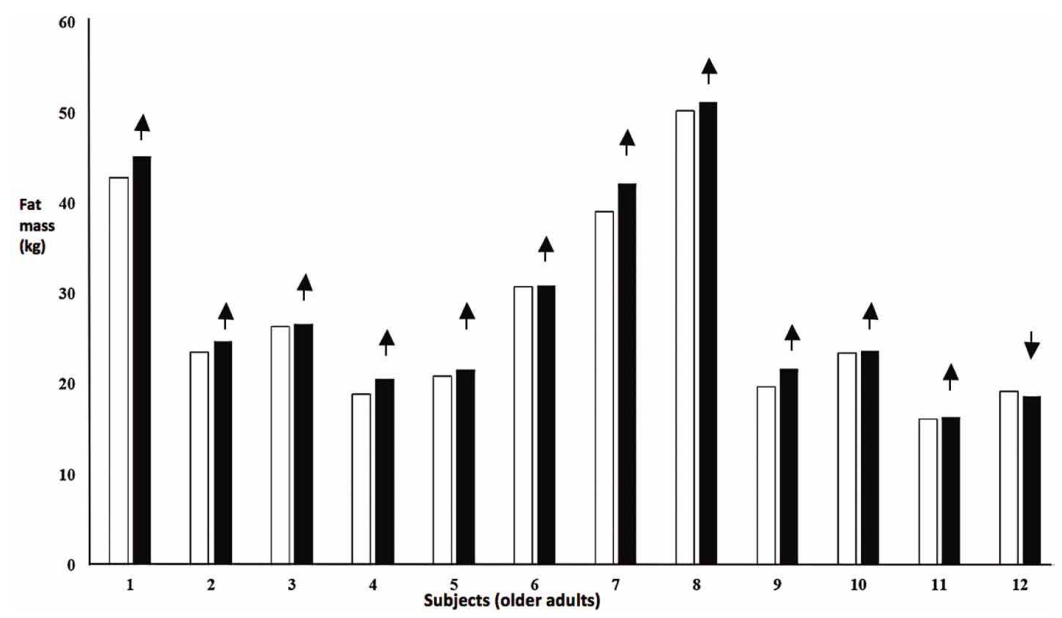

Fig. 1. Changes in fat mass during summer holiday (2015) in older adults from Valparaíso, Chile. White bars indicate pre holiday season and black bars indicate post holiday season. The black arrow indicate change between pre and post holiday.

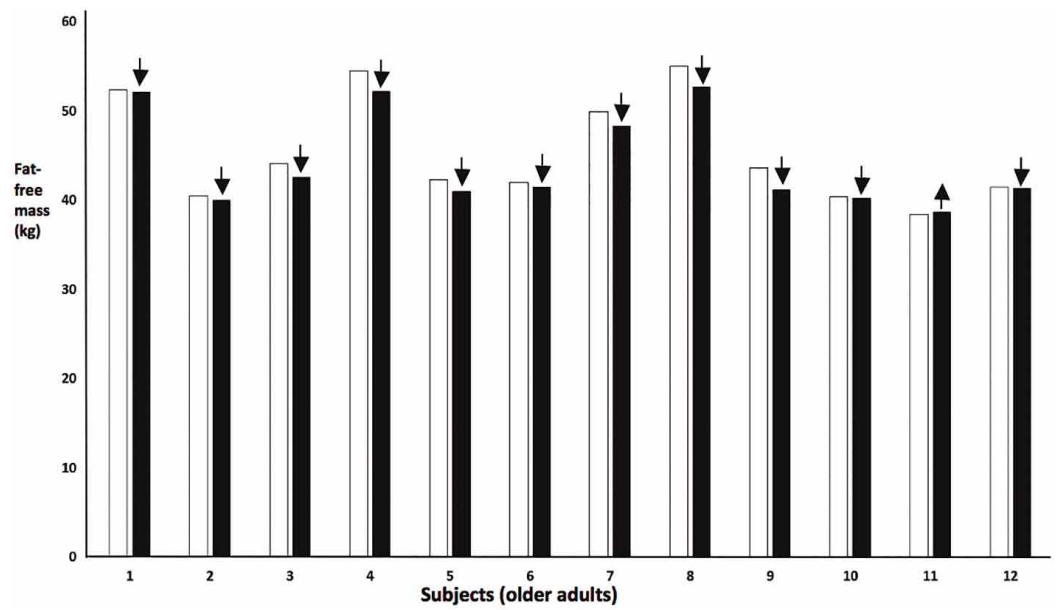

Fig. 2. Changes in fat free mass during summer holiday (2015) in older adults from Valparaíso, Chile. White bars indicate pre holiday season and black bars indicate post holiday season. The black arrow indicate change between pre and post holiday.

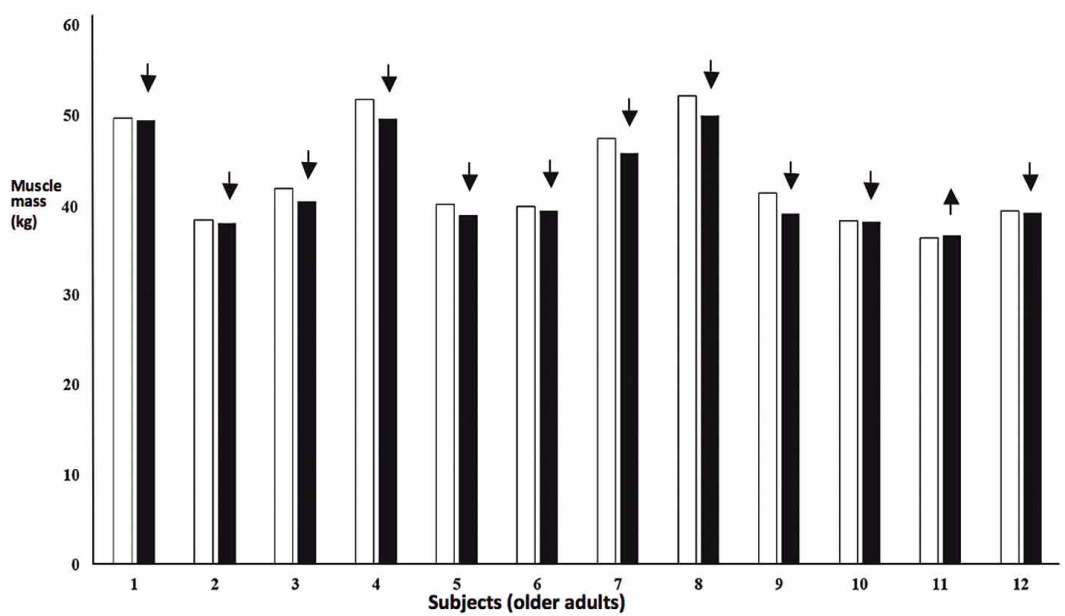

Fig. 3. Changes in muscle mass during summer holiday (2015) in older adults from Valparaíso, Chile. White bars indicate pre holiday season and black bars indicate post holiday season. The black arrow indicate change between pre and post holiday. increased (Fig. 1), and eleven participants $(91.67 \%)$ showed a decrease in FFM and MM (Fig. 1 and 2, respectively). All the subjects that presented an increase in FM also showed a decrease in MM, representing the 100 per cent (view Figs. 1 and 3).

\section{DISCUSSION}

This study showed changes in body composition of OA in a relative short period of time; mainly FM increase and MM decrease. However, BMI was not a good indicator of changes in body composition during summer holidays for OA. This finding could be because BMI does not account for differences in the proportion of body (Prado et al., 2015; Rothman, 2008). This hypothesis aligns with our data as the evaluated OA gained a significant amount of FM and decreased MM and FFM during the evaluation period. This implies that decreases in MM and increases in FM occurred though the subjects maintained their weight and BMI (Gallagher et al., 2000). Changes in body composition over the holiday season have been reported by Payab et al. who described a significant increase in weight and BMI and a (non-significant) decrease in FM. Other studies reported significant increase in weight and \% FM, mainly in obese participants (Stevenson et al.). On the other hand, Yanovski et al. (2000) reported that these increases in body fat percentage do not seem to be reversed in the following months. Therefore, monitoring of FM gained seems to be of particular importance for early prevention of overweight and eventually obesity.

Some limitations apply to this study. A first limitation is its reduced number of participants, but preliminary results are useful for justifying additional studies using a larger sample to support new prevention strategies that change norms and improve healthy lifestyles in OA during this life stage. A second limitation is that participants were drawn from one Commune of the Valparaíso region, Chile, and may not represent other geographic localities. 
Our findings suggest further studies to improve the accuracy of the nutritional diagnostic guidance for OA regarding body composition (Prado et al.; Prentice \& Jebb, 2001) and special prevention strategies on the holiday season in Chilean OA.

\section{ACKNOWLEDGEMENTS}

We would like to thank Paula Cisternas-Vallejos and Gustavo Vega-Fernandez for their collaboration in collecting the anthropometric measurements, and to Alonso Hormazábal-Peralta for his helpful comments. In addition, the authors are grateful to the Dirección de Investigación, Vice-rectoría de Investigación y Estudios Avanzados and the Instituto de Biología and Escuela de Kinesiología of the Facultad de Ciencias of the Pontificia Universidad Católica de Valparaíso, Chile, for their constant support.

LIZANA, P. A.; LÓPEZ, R. \& ALBALA, C. Efecto de las vacaciones de verano en la composición corporal de adultos mayores, insuficiencia del índice de masa corporal para detectar cambios durante un período crítico: Un estudio piloto. Int. J. Morphol., 34(2):557-560, 2016.

RESUMEN: La obesidad es el principal problema de salud en todo el mundo. La prevalencia de obesidad en adultos mayores (AM) chilenos es cada vez mayor, lo que se ha asociado con varios efectos negativos para la salud. Por lo tanto, la determinación de períodos críticos de aumento de la adiposidad es relevante en AM. El objetivo fue evaluar los cambios de la composición corporal en adultos mayores AM durante las vacaciones de verano. Doce AM participaron en una evaluación inicial (E1) y final (E2) del verano 2015. Se evaluó: peso, talla, índice de masa corporal (IMC), masa libre de grasa (MLG), masa grasa (MG) y masa muscular (MM). No hubo diferencias significativas en peso e IMC. La MG aumentó entre E1 $(27,63 \pm 10,91)$ y E2 $(28,64 \pm 11,39)$ (p= $0,007)$, la MLG disminuyó significativamente entre E1 $(45,38 \pm 5,89)$ y E2 $(44,33 \pm 5,36)$, como también la MM entre E1 $(43,08 \pm 5,62)$ y E2 $(42,07 \pm 5,10)$. Tanto el peso como el IMC son medidas insuficientes para detectar cambios durante este período crítico de vacaciones de verano. Sin embargo, las medidas de la composición corporal identificaron cambios significativos en AM durante el estudio.

PALABRAS CLAVE: Sarcopenia; Grasa corporal; Obesidad; Impedancia bioelectrica.

\section{REFERENCES}

Berry, S. D.; McLean, R. R.; Hannan, M. T.; Cupples, L. A. \& Kiel, D. P. Changes in bone mineral density may predict the risk of fracture differently in older adults according to fall history. J. Am. Geriatr. Soc., 62(12):2345-9, 2014.

Gallagher, D.; Ruts, E.; Visser, M.; Heshka, S.; Baumgartner, R. N.; Wang, J.; Pierson, R. N.; Pi-Sunyer, F. X. \& Heymsfield, S. B. Weight stability masks sarcopenia in elderly men and women. Am. J. Physiol. Endocrinol. Metab., 279(2):E366-75, 2000.
Gómez-Cabello, A.; Vicente Rodríguez, G.; Vila-Maldonado, S.; Casajús, J. A. \& Ara, I. Aging and body composition: the sarcopenic obesity in Spain. Nutr. Hosp., 27(1):22-30, 2012.

Janssen, I.; Heymsfield, S. B. \& Ross, R. Low relative skeletal muscle mass (sarcopenia) in older persons is associated with functional impairment and physical disability. J. Am. Geriatr. Soc., 50(5):88996, 2002.

Ministerio de Salud (MINSAL). Encuesta Nacional de Salud ENS Chile 2009-2010. Santiago de Chile, Gobierno de Chile, 2011. Available from: http://web.minsal.cl/portal/url/item/ bcb03d7bc28b64dfe040010165012d23.pdf

Ministerio de Salud (MINSAL). Manual de Aplicación del Examen de Medicina Preventiva del Adulto Mayor. Santiago de Chile, Gobierno de Chile, 2015. Available from: http://www.minsal.gob.cl/portal/url/ item/ab1f81f43ef0c2a6e04001011e011907.pdf

Parr, E. B.; Coffey, V. G. \& Hawley, J. A. 'Sarcobesity': a metabolic conundrum. Maturitas, 74(2):109-13, 2013.

Payab, M.; Hasani-Ranjbar, S.; Zahedi, H.; Qorbani, M.; Shateri, Z.; Larijani, B. \& Soroush, A. The effect of Norouz holiday on anthropometric measures and body composition. J. Diabetes Metab. Disord., 14:7, 2015.

Prado, C. M.; Gonzalez, M. C. \& Heymsfield, S. B. Body composition phenotypes and obesity paradox. Curr. Opin. Clin. Nutr. Metab. Care, 18(6):535-51, 2015.

Prentice, A. \& Jebb, S. A. Beyond body mass index. Obes. Rev., 2(3):1417, 2001.

Rothman, K. J. BMI-related errors in the measurement of obesity. Int. J. Obes. (Lond.), 32 (Suppl. 3):S56-9, 2008.

Ryan, A. S. \& Nicklas, B. J. Age-related changes in fat deposition in midthigh muscle in women: relationships with metabolic cardiovascular disease risk factors. Int. J. Obes. Relat. Metab. Disord., 23(2):126-32, 1999.

Stevenson, J. L.; Krishnan, S.; Stoner, M. A; Goktas, Z. \& Cooper, J. A. Effects of exercise during the holiday season on changes in body weight, body composition and blood pressure. Eur. J. Clin. Nutr., 67(9):944-9, 2013.

Yanovski, J. A.; Yanovski, S. Z.; Sovik, K. N.; Nguyen, T. T.; O'Neil, P. M. \& Sebring, N. G. A prospective study of holiday weight gain. N. Engl. J. Med., 342(12):861-7, 2000.

Correspondence to:

Dr. Pablo A. Lizana

Laboratory of Morphological Sciences

Instituto de Biología

Pontificia Universidad Católica de Valparaíso

Campus Curauma

Avenida Universidad 330

Valparaíso

CHILE

Email address: pablo.lizana@pucv.cl

Received: 10-01-2016

Accepted: 06-04-2016 